\title{
The PTEN/PI3K pathway governs normal vascular development and tumor angiogenesis
}

\author{
Koichi Hamada, ${ }^{1}$ Takehiko Sasaki, ${ }^{2}$ Pandelakis A. Koni, ${ }^{4}$ Miyuki Natsui, ${ }^{1}$ Hiroyuki Kishimoto, ${ }^{1}$ \\ Junko Sasaki, ${ }^{1,2}$ Nobuyuki Yajima, ${ }^{1}$ Yasuo Horie, ${ }^{1,3}$ Go Hasegawa, ${ }^{5}$ Makoto Naito, ${ }^{5}$ \\ Jun-ichi Miyazaki, ${ }^{6}$ Toshio Suda, ${ }^{7}$ Hiroshi Itoh, ${ }^{8}$ Kazuwa Nakao, ${ }^{8}$ Tak Wah Mak, ${ }^{9,11}$ \\ Toru Nakano, ${ }^{10,11}$ and Akira Suzuki ${ }^{1,11,12}$ \\ ${ }^{1}$ Department of Molecular Biology, ${ }^{2}$ Department of Microbiology, ${ }^{3}$ Department of Gastroenterology, Akita University \\ School of Medicine, Akita 010-8543, Japan; ${ }^{4}$ Molecular Immunology Program, Institute of Molecular Medicine and Genetics, \\ Medical College of Georgia, Augusta, Georgia 30912, USA; ${ }^{5}$ Department of Cellular Function, Niigata University Graduate \\ School of Medical and Dental Sciences, Niigata 951-8510, Japan; ${ }^{6}$ Division of Stem Cell Regulation Research, Osaka \\ University Graduate School of Medicine, Suita 565-0871, Japan; ${ }^{7}$ Department of Cell Differentiation, The Sakaguchi \\ Laboratory, School of Medicine, Keio University School of Medicine, Tokyo 160-8582, Japan; ${ }^{8}$ Department of Medicine and \\ Clinical Science, Kyoto University Graduate School of Medicine, Kyoto 606-8507, Japan; ${ }^{9}$ The Campbell Family Institute of \\ Breast Cancer Research, and Departments of Immunology and Medical Biophysics, University of Toronto, Toronto M5G \\ 2C1, Ontario, Canada; ${ }^{10}$ Department of Pathology, Medical School and Graduate School of Frontier Biosciences, Osaka \\ University, Suita 565-0871, Japan
}

PTEN is an important tumor suppressor gene. Hereditary mutation of PTEN causes tumor-susceptibility diseases such as Cowden disease. We used the Cre-loxP system to generate an endothelial cell-specific mutation of Pten (Tie2CrePten) in mice. Tie2CrePten ${ }^{f l o x /+}$ mice displayed enhanced tumorigenesis due to an increase in angiogenesis driven by vascular growth factors. This effect was partially dependent on the PI3K subunits $p 85 \alpha$ and $p 110 \gamma$. In vitro, Tie2CrePten ${ }^{f l o x /+}$ endothelial cells showed enhanced proliferation/ migration. Tie2CrePten ${ }^{\text {flox/flox }}$ mice died before embryonic day 11.5 (E11.5) due to bleeding and cardiac failure caused by impaired recruitment of pericytes and vascular smooth muscle cells to blood vessels, and of cardiomyocytes to the endocardium. These phenotypes depend strongly on $p 110 \gamma$ rather than on $p 85 \alpha$ and were associated with decreased expression of Ang-1, VCAM-1, connexin 40, and ephrinB2 but increased expression of Ang-2, VEGF-A, VEGFR1, and VEGFR2. Pten is thus indispensable for normal cardiovascular morphogenesis and post-natal angiogenesis, including tumor angiogenesis.

[Keywords: PTEN; PI3K; endothelial cells; cardiovasculogenesis; tumor angiogenesis]

Supplemental material is available at http://www.genesdev.org.

Received February 22, 2005; revised version accepted June 27, 2005.

PTEN is a tumor suppressor gene (Li et al. 1997) that is mutated in many human sporadic cancers and in hereditary tumor susceptibility disorders such as Cowden disease (Liaw et al. 1997). PTEN is a multifunctional phosphatase whose major substrate is phosphatidylinositol3,4,5-trisphosphate (PIP3) (Maehama and Dixon 1998), a lipid second messenger molecule. PIP3 activates numerous downstream targets, including the serine-threonine kinase $\mathrm{PKB} / \mathrm{Akt}$, which is involved in anti-apoptosis, proliferation, and oncogenesis (Gerber et al. 1998). By using its lipid phosphatase activity to dephosphorylate

\footnotetext{
${ }^{11}$ These authors contributed equally to this work.

${ }^{12}$ Corresponding author.

E-MAIL suzuki@med.akita-u.ac.jp; FAX 81-18-884-6077.

Article published online ahead of print. Article and publication date are at http://www.genesdev.org/cgi/doi/10.1101/gad.1308805.
}

PIP3, PTEN negatively regulates the phosphoinositide3-kinase (PI3K)-PKB/Akt pathway and thus exerts tumor suppression. PI3K family members are classified into three groups according to their structures and substrate specificities. Among them, class I PI3Ks produce PIP3 and are involved in receptor-mediated signaling. Class I PI3Ks are further divided into two subclasses. Class IA heterodimeric PI3Ks, consisting of a catalytic subunit $(p 110 \alpha, p 110 \beta, p 110 \delta)$ and a regulatory subunit $(p 85 \alpha$, $p 85 \beta, p 55 \gamma)$, are involved in receptor tyrosine kinase (RTK) pathways, whereas class IB PI3K (p110 $\gamma)$ acts downstream of G-protein-coupled receptors (GPCRs). Both classes of PI3Ks can be activated by a wide range of vascular growth factors (VGFs).

Embryonic cardiovascular development and post-natal neovascularization (including tumor angiogenesis) are 
complex processes that share signaling molecules (Daniel and Abrahamson 2000). These processes depend on shear stress and coordinated interactions between endothelial VGFs (e.g., VEGF, Ang-1, Ang-2, bFGF, PDGF-B, ephrin-B2, TGF- $\beta$ superfamily members), intracellular signaling molecules (e.g., Notch1, COUP-TFII), and intercellular contacts (e.g., connexins, VCAM-1). Mutations of these molecules cause defects in cardiovascular development (Dickson et al. 1995; Suri et al. 1996; Lindahl et al. 1997; Larsson et al. 2001; Lindblom et al. 2003). Significantly, all of the above growth factors also activate the PI3K-PKB/Akt pathway.

Normal cardiovascular development requires communication between endothelial cells and surrounding mesenchymal cells (Suri et al. 1996; Hellstrom et al. 2001). The vascular wall is composed of endothelial cells that surround the lumen of the vessel, backed by layers of pericytes (PCs) in microvessels, or vascular smooth muscle cells (vSMCs) in large vessels (Hungerford and Little 1999). Cross-talk between endothelial cells and PCs or vSMCs is critical for vascular remodeling and maturation. Defects in PC/vSMC recruitment, such as result from mutations abrogating signaling via PDGF-B (Lindahl et al. 1997), Ang-1 (Suri et al. 1996), or TGF- $\beta$ (Dickson et al. 1995), result in vascular abnormalities.

PTEN is important for normal cardiovascular homeostasis. In vitro, PTEN inhibits vascular sprouting and endothelial tube formation induced by VEGF; dominantnegative mutation of PTEN abolishes these effects (Huang and Kontos 2002). Su et al. (2003) have shown that tumor angiogenesis and tumor growth in vivo are blocked by Pten overexpression in tumor cells or by administration of PI3K inhibitors. However, it was not clear in that study whether the inhibition of tumor growth was caused by the angiogenesis defect or by a direct effect on the tumor cells. Here we demonstrate that the role of PTEN in cardiovasculogenesis and angiogenesis is to regulate the expression of vascular signaling molecules, particularly VGFs.

\section{Results \\ Generation of endothelial cell-specific Pten-deficient mice}

We generated a conditional Pten knockout mouse in which Pten expression was governed by Tie2, an endothelial cell-specific promoter. Pten exon 5, which encodes the phosphatase domain, was flanked with $\operatorname{lox} P$ sequences (Ptenflox) (Fig. 1A; Suzuki et al. 2001). Pten flox/flox males were crossed with Pten flox/+ females that carried a single Tie2Cre transgenic locus (Koni et al. 2001) coupled to a reporter transgene (CAG-loxP-CAT-loxPEGFP) (Kawamoto et al. 2000). Analysis of reporterpositive Tie2Cre progeny showed that recombination occurred mainly in endocardial cells and systemic endothelial cells but not in PCs/vSMCs (Fig. 1B). PCR examination of DNA from embryonic day 9.5 (E9.5) cells positive for the endothelial cell marker VEGFR2 confirmed that efficient Cre-mediated recombination had occurred in the Tie2CrePten flox/flox mice. Quantitation of recombination was established in preliminary PCR experiments using mixtures of various ratios of Pten $^{\Delta}$ and Pten $^{\text {flox }}$ plasmid DNAs under identical PCR conditions (Fig. 1C). The recombination frequency in VEGFR2 ${ }^{+}$ cells of Tie2CrePten flox/flox mice was $\sim 95 \%$ (Fig. 1D).

\section{Increased angiogenesis and accelerated tumor growth in Tie2CrePten ${ }^{\text {flox/+ }}$ mice}

Histological analyses of systemic vessels and the heart revealed no significant structural differences between Tie2CrePten $^{+/+}$and Tie2CrePten ${ }^{\text {flox/+ }}$ mice (data not shown). Since VGFs activate the PI3K-PKB/Akt pathway, we investigated whether VGF-stimulated angiogenesis was increased in Tie2CrePten ${ }^{\text {flox/+ }}$ mice. Matrigel implants impregnated with $b \mathrm{FGF}, b \mathrm{FGF}+\mathrm{VEGF}, b \mathrm{FGF}+$ Ang-1, or PBS were administered subcutaneously to Tie2CrePten ${ }^{+/+}$ and Tie2CrePten ${ }^{\text {flox/+ }}$ mice. Blood vessel infiltration of the implants was quantified by immunostaining with
A

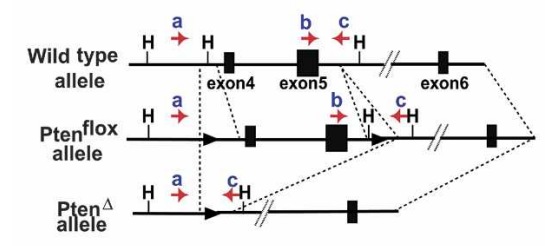

C

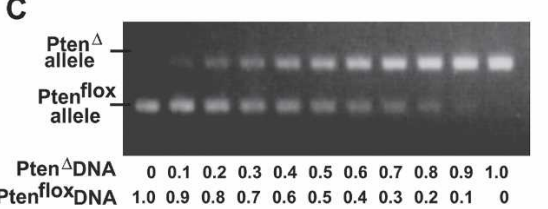

B

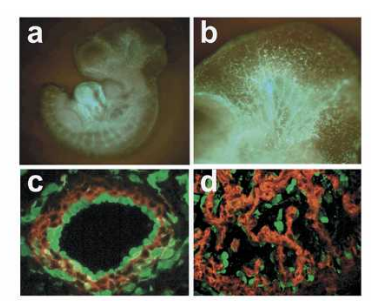

D

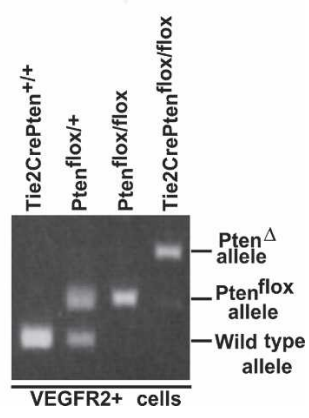

Figure 1. Generation of endothelial cell-specific Pten-deficient (Tie2CrePten ${ }^{\text {flox/flox }}$ ) mice. (A) Targeting strategy. Exons of the murine Pten gene are represented by $\mathbf{m}$, and $\operatorname{lox} P$ sites are indicated by black arrowheads. The floxed $\left(\right.$ Pten $\left.^{\text {flox }}\right)$ and deleted $\left(\right.$ Pten $\left.^{\Delta}\right)$ alleles are shown. Primers used for genotyping are shown as red arrows $(\mathrm{a}-\mathrm{c})$. $(B)$ Tissue distribution of Tie2Cre-mediated recombination. Immunohistochemistry was used to evaluate GFP expression at E9.5 (panels $a, b$ ), and GFP plus SMA (red) expression in the dorsal aorta (panel $c$ ) and heart (panel $d$ ) at E10.5, in Tie2Cre Tg mice carrying the reporter transgene. (C) Quantitation of genomic PCR. A total of $1 \mathrm{fg}$ of a mixture of various ratios of $P_{t e n}{ }^{\Delta}$ and Pten ${ }^{\text {flox }}$ plasmid DNAs was used as template DNA. (D) Deletion of the Pten gene. Genomic PCR of DNA from VEGFR2 ${ }^{+}$cells in E9.5 embryos of the indicated genotype. In Tie2CrePten ${ }^{\text {flox/flox }}$ mice, the vast majority of VEGFR2 ${ }^{+}$cells showed deletion of the Pten gene. PCR conditions were identical to those in $C$. 
anti-CD31 antibody. In contrast to implanted Tie2CrePten ${ }^{+/+}$ mice, implanted Tie2CrePten ${ }^{\text {flox/+ }}$ mice showed increased vascularization, even in PBS controls (Fig. 2A). Moreover, angiogenic responses to VGFs were significantly elevated in the mutants (Fig. 2A,B).

To determine whether heterozygous Pten deficiency in endothelial cells affected adult tumor angiogenesis, Tie2CrePten ${ }^{\text {flox/+ }}$ and Tie2CrePten ${ }^{+/+}$mice were injected subcutaneously with either melanoma (B16BL6) or Lewis lung carcinoma (LLC) cells. Both cell lines induced significantly larger tumors in Tie2CrePten flox/+ mice than in Tie2CrePten ${ }^{+/+}$mice (Fig. 2C [top], D). When tumor sections were immunostained with antiCD31, microvessels were evident in tumors from both Tie2CrePten $^{+/+}$and Tie2CrePten ${ }^{\text {flox/+ }}$ mice, but were more abundant and of larger size in the latter (Fig. 2C [bottom], E). Vessel density in nontumorous adult skin was comparable between Tie2CrePten ${ }^{\text {flox/+ }}$ and Tie2CrePten ${ }^{+/+}$ mice (Supplementary Fig. 1A,B).

We next used PCNA staining and the Transwell system to evaluate the proliferation and migration, respectively, of mouse lung endothelial cells (MLECs) from 10wk-old Tie2CrePten ${ }^{+/+}$and Tie2CrePten ${ }^{\text {flox/+ }}$ mice. In response to stimulation with Ang-1 or VEGF-A, total numbers of $\mathrm{PCNA}^{+}$cells and their migration were significantly increased in Tie2CrePten ${ }^{\text {flox/+ }}$ cultures compared with controls (Fig. 2F).

Because Tie2 is expressed in hemangioblasts as well as in endothelial cells, Tie2Cre also deletes the Pten gene in hematopoietic cells. However, numbers and subsets of $\mathrm{T}$ cells, NK cells, and NKT cells were all normal in Tie2CrePten flox/+ mice (Supplementary Fig. 2A,B). Tie2CrePten ${ }^{\text {flox/+ }}$ splenocytes stimulated with either IL12 or anti-CD3 plus anti-CD28 showed normal IFN- $\gamma$ secretion (Supplementary Fig. 2C). Because macrophages are crucial for pathological angiogenesis (Bingle et al. 2002), we repeated the above Matrigel and tumor cell implantation experiments using LysMCrePten ${ }^{\text {flox/+ }}$ mice. In these mutant animals, the Pten gene is heterozygously deleted in $>80 \%$ of peritoneal macrophages (data not shown). No differences in tumor angiogenesis were observed between the LysMCrePten ${ }^{+/+}$and LysMCrePten ${ }^{\text {flox/+ }}$ genotypes (Supplementary Fig. 2D-F). Thus, the accelerated tumor growth in Tie2CrePten ${ }^{\text {flox/+ }}$ mice results from enhanced angiogenesis driven by increased endothelial cell proliferation/migration and not from defects in macrophages or tumor immunosurveillance.
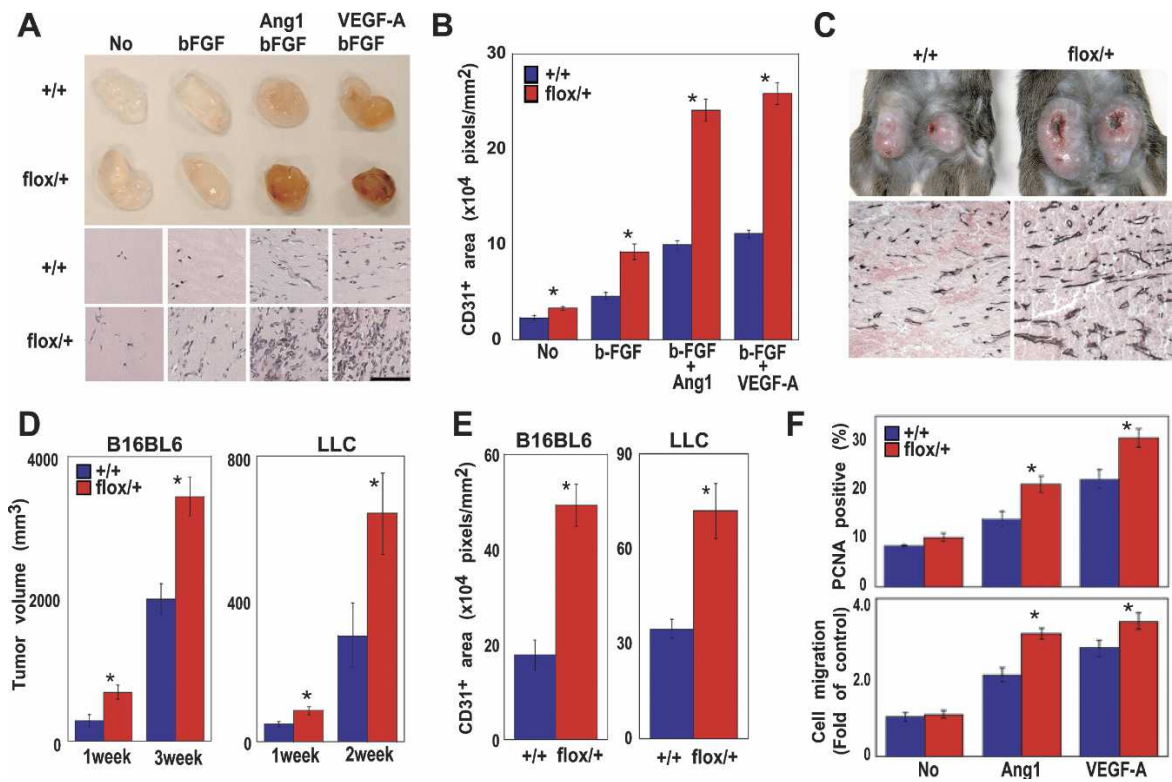

Figure 2. Tie2CrePten ${ }^{\text {flox } /+}$ mice show increased angiogenesis and accelerated tumor growth. $(A, B)$ Increased angiogenesis in response to VGFs. $(A$, top $)$ Representative photos of Matrigel plugs containing no growth factors (No), $b$ FGF, $b$ FGF + Ang- 1 , or $b$ FGF + VEGF-A. Plugs were removed from Tie2CrePten ${ }^{++}(+/+)$and Tie2CrePten ${ }^{f l o x} /+($ flox $/+)$ mice at $14 \mathrm{~d}$ post-injection. Plug vascularization is accelerated in the mutant. (Bottom) Anti-CD31 staining of sections of the Matrigel plugs in the top panel. Numbers of endothelial cells and vessel structures are increased in the mutant. $(B)$ Quantitated vascularization of Matrigel plugs. The area of a plug staining positively with anti-CD31 was quantitated using NIH image software. Significant $\left({ }^{\star}\right)$ increases in plug vascularization in response to VGFs were observed in Tie2CrePten ${ }^{\text {flox } /+}$ mice (flox $\left./+; n=8\right)$ compared with wild-type littermates $(n=8)$. (C-E) Increased tumor growth. $(C, t o p)$ Representative photos of LCC cells at 2 wk post-implantation in Tie2CrePten ${ }^{+/+}$and Tie2CrePten ${ }^{\text {flox/+ }}$ mice. (Bottom) Anti-CD31 staining of sections of the tumors in the top panels, showing an increased number of endothelial cells and vessel structures in the mutant. $(D)$ Tumor volumes $1-3 \mathrm{wk}$ after transplantation of B16BL6 melanomas $(n=4$ mice/genotype) or LLC cells ( $n=6$ mice/genotype). (E) Quantitation of tumor vascularization 2 wk after implantation of tumor cells in $D$. (F) Enhanced proliferation and migration of Tie2CrePten ${ }^{\text {flox/+ }}$ MLECs after stimulation by Ang-1 or VEGF-A. (Top) Proliferation of VGF-stimulated MLECs as measured by PCNA immunostaining. (Bottom) Migration of MLECs cultured in Transwell cultures for $4 \mathrm{~h}$ in the presence of the indicated VGF. For $B, D, E$, and $F$, results are expressed as the mean \pm SEM and are representative of three trials. Statistical differences were determined using the Student's $t$-test; $\left.\right|^{\star} \mid p<0.05$. 
Death of Tie2CrePten ${ }^{\text {flox/flox }}$ mice by E11.5 due to cardiac failure and bleeding

The life expectancy, fertility, and gross appearance of viable F1 and F2 Tie2CrePten flox/+ mice appeared normal, but no Tie2CrePten ${ }^{\text {flox } / \text { flox }}$ mice were found among 108 offspring from Tie2CrePten ${ }^{\text {flox/+ }}$ and Pten ${ }^{\text {flox/flox }}$ intercrosses. Genotyping of 230 progeny of these intercrosses at various embryonic stages showed that homozygous mutant embryos were present at the expected Mendelian frequency up to E9.5, but that resorption commenced at E10.5 and embryonic loss occurred at E11.5 (Table 1).

Histologically, E8.25 Tie2CrePten ${ }^{\text {flox/flox }}$ embryos were essentially normal with respect to gross appearance of the central vascular tree (Fig. 3A, panels a,b), including the rostral-caudal aorta (red arrows), and the anterior and posterior cardiac veins (Fig. 3A, panels $\mathrm{c}-\mathrm{f}$, blue arrows). Pten is thus dispensable for the differentiation of angioblasts from the ventral mesoderm, their appropriate migration within the embryo, and their alignment to form major vessels. However, most E8.25 homozygous mutants exhibited delayed heart looping (Fig. 3A, panels g,h, yellow arrows) and enlarged and partially fused yolk sac vessels (Fig. 3A, panels i,j; green arrow). By E9.0, the mutant allantois had connected normally to the chorion (Fig. 3B), but by E9.5, the capillary plexus was enlarged (Fig. 3C, panels a,b, yellow arrows) and distinct branches of large vessels such as the anterior cardinal vein were not formed (Fig. 3C, panels c,d, red arrow) because of a failure in primary vascular plexus remodeling. Vascular sprouting into the neural tube was barely detectable (Fig. $3 \mathrm{C}$, panels e,f, blue arrow). Tie2CrePten flox/flox embryos also failed to generate distinct vitelline vessels in the yolk sac (Fig. 3D, panels a-d), showing instead a meshwork of interconnected, oversized endothelial cell-lined tubes (Fig. 3D, panels e,f). Dilated capillary-plexus vessels filled the intercapillary spaces (Fig. 3D, panels g,h).

Growth retardation was observed in $50 \%$ of E9.5 Tie2CrePten ${ }^{\text {flox/flox }}$ embryos. By E10.5, the majority of mutants showed profound growth retardation as well as pericardial cavity enlargement and frequent bleeding into the pericardial cavity (Fig. 3E, panels a-f, red arrows) or large trunk vessels (Fig. 3E, panel g, blue arrows). Numbers of primitive hematopoietic cells in Tie2CrePten flox/flox blood vessels were normal from E8.25 to E10.5 (data not shown).
Morphometric analyses showed that vessels in Tie2CrePten flox/flox yolk sacs were fewer in number (Supplementary Fig. 3A) but larger in diameter (Supplementary Fig. 3B/ than in controls. Tie2CrePten flox/flox yolk sacs also showed an increase in endothelial cell numbers (Supplementary Fig. 3C) that was attributable to proliferation, as judged by their increased staining for Ki67, a nuclear protein highly expressed in proliferating cells (Supplementary Fig. 3D). TUNEL assays revealed no significant differences in numbers of apoptotic endothelial cells in mutant and wild-type yolk sacs (data not shown). No vascular abnormalities were evident in E8.5E11.5 Tie2CrePten ${ }^{\text {flox/+ }}$ embryos. Thus, enhanced endothelial cell proliferation and impaired vascular remodeling are likely responsible for the lethal vascular phenotype of Tie2CrePten ${ }^{\text {flox/flox }}$ embryos.

Impaired recruitment of PCs and VSMCs and defective cardiac muscle development in Tie2CrePten ${ }^{\text {flox/flox }}$ mice

We examined PC and vSMC recruitment using immunostaining with anti-smooth muscle antigen antibody $(\alpha \mathrm{SMA})$. At E10.0, $\alpha \mathrm{SMA}^{+}$cells were observed in perivascular regions of the Tie2CrePten ${ }^{+/+}$yolk sac (Fig. 3F, panel a) and in the placental extraembryonic circulation (data not shown). In contrast, no $\alpha \mathrm{SMA}^{+} \mathrm{PCs} / \mathrm{vSMCs}$ were observed adjacent to endothelial cells in Tie2CrePten flox/flox vessels either in the yolk sac (Fig. 3F, panel b) or placenta (data not shown). In the embryo proper, $\alpha$ SMA staining observed in the vessels, heart, and dorsal aorta of wildtype embryos (Fig. 3F, panels c,e) was dramatically reduced in Tie2CrePten flox/flox embryos (Fig. 3F, panels $\mathrm{d}, \mathrm{f})$. Electron micrographs of E9.5 Tie2CrePten flox/flox yolk sacs and placenta confirmed the absence of PCs around the capillary network endothelium (Fig. 3F, panel h). The observed bleeding from the large trunk vessels may result from the impaired recruitment of PCs/ vSMCs to these tissues. A reduction in the size of the developing intraventricular septum and cardiac trabeculae, and a thinning of the cardiac wall (Fig. 3F, panel f), were also observed in homozygous mutants. The thinnest cardiac walls resembled membranes (Fig. 3F, panel f, blue arrow) such that bleeding in the mutant pericardial cavity could have resulted from cardiac wall rupture or leakage of blood cells from the cardiac lumen. Because

Table 1. Genotyping of mice derived from Tie2CrePten ${ }^{\text {flox/+ }}$ female and $\mathrm{Pten}^{\text {flox/flox }}$ male intercrosses

\begin{tabular}{|c|c|c|c|c|c|}
\hline \multirow[b]{2}{*}{ Age (days) } & \multicolumn{2}{|c|}{ Number of genotypes } & \multirow[b]{2}{*}{ Tie2CrePten ${ }^{\text {flox/+ }}$} & \multirow[b]{2}{*}{ Tie2CrePten ${ }^{\text {flox/flox }}$} & \multirow{2}{*}{$\begin{array}{c}\text { No. resorbed } \\
\text { embryos }^{\mathrm{a}}\end{array}$} \\
\hline & Pten $^{\text {flox } /+}$ & Pten flox/flox & & & \\
\hline E9.5 & 25 & 19 & 18 & $20(15)$ & 0 \\
\hline E10.5 & 24 & 25 & 21 & $16(16)$ & 7 \\
\hline E11.5 & 18 & 12 & 13 & 0 & 12 \\
\hline P0 & 13 & 15 & 13 & 0 & \\
\hline P21-28 & 25 & 21 & 21 & 0 & \\
\hline
\end{tabular}

Genotypes of mice at indicated post-natal (P) or embryonic (E) days were determined using PCR analysis. Numbers in parentheses indicate the total number of abnormal Tie2CrePten ${ }^{\text {flox/flox }}$ embryos counted under a microscope.

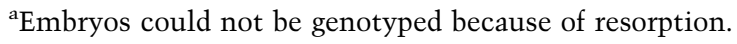




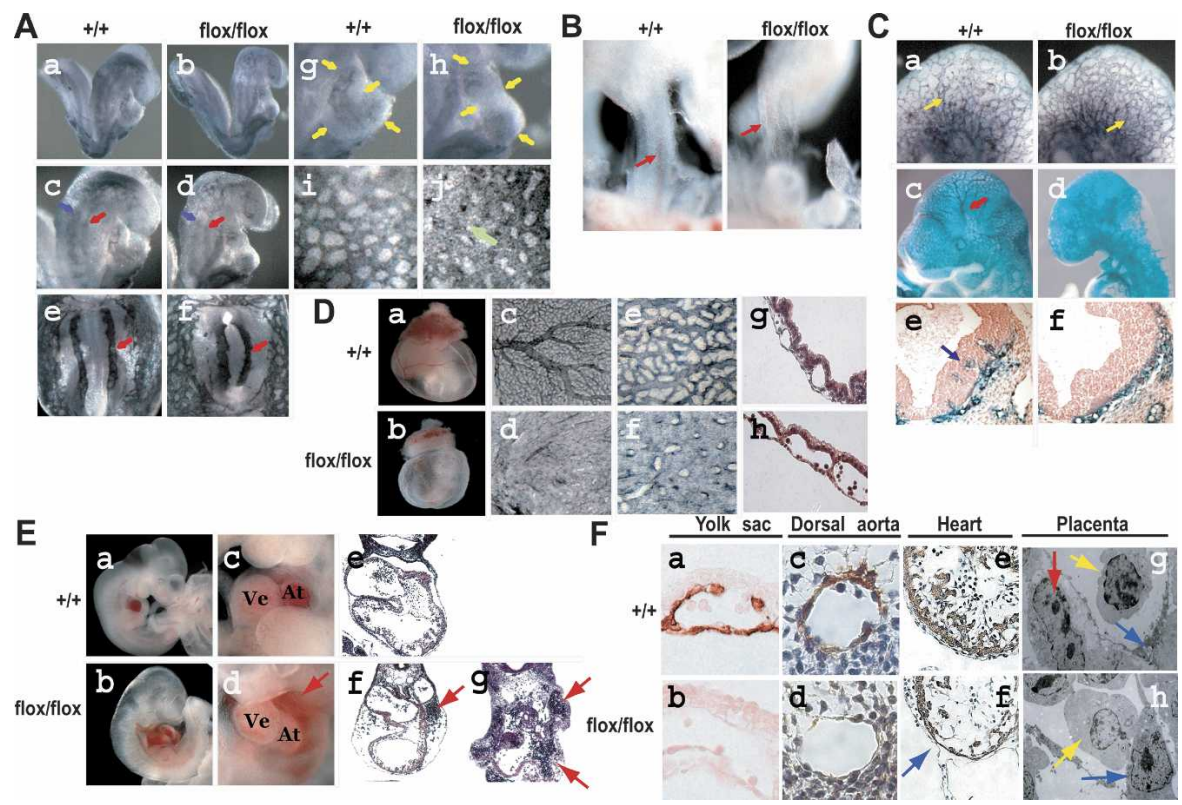

Figure 3. Cardiovascular defects in Tie2CrePten flox/flox embryos. (A) Whole mounts of E8.25 embryos immunostained with antiCD31. (Panels $a-f$ ) Vascular tree components, including the rostral-caudal aorta (red arrows) and anterior and posterior cardiac veins (blue arrows), were grossly normal in Tie2CrePten flox/flox embryos. (Panels g-j) Delayed heart looping (yellow arrows) and enlarged and partially fused yolk sac vessels (green arrow) were apparent in the mutant. (B) Normal chorioallantoic fusion in E9.0 Tie2CrePten flox/flox embryos. (C) Gross abnormalities in E9.5 Tie2CrePten flox/flox embryos. Anti-CD31 staining of whole-mount (panels $a, b)$, gross wholemount (panels $c, d$ ), and histological LacZ staining (panels $e, f$ ) of E9.5 embryos are shown for Tie2CrePten ${ }^{+/+}$and Tie2CrePten ${ }^{\text {flox/flox }}$ embryos carrying the Flk-1+/- LacZ transgene. The mutant shows an enlarged capillary plexus (yellow arrows; panels $a, b$ ), a failure to remodel distinct branches of the anterior cardinal vein (red arrow; panel $c$ ), and impaired vascular sprouting into the neural tube (bottom, blue arrow; panel e). (D) Abnormalities in the E9.5 yolk sac. Whole mounts of E9.5 yolk sac (panels $a, b$ ), and anti-CD31 staining of yolk sac tissues (panels $c-f$ ), and H\&E staining of yolk sac tissues (panels $g, h$ ) are shown. (Panels $a-d$ ) A failure of vascular remodeling to form mature distinct vitelline vessels can be clearly seen in the homozygous mutant yolk sac. (Panels $e-h)$ Interconnected and homogeneously dilated endothelial cell-lined tubes are present. (E) Fatal cardiovascular abnormalities. E10.5 Tie2CrePten ${ }^{\text {flox/flox }}$ embryos showed an enlarged pericardial cavity, and frequent bleeding (red arrows) in the cavity (panels $\left.b, d, f\right)$ or in large trunk vessels (panel $g$ ). Panels $e-g$ show H\&E staining. (At) Atrium; (Ve) ventricle. (F) Decreased $\alpha$-SMA expression in mutant embryonic vasculature (panels $a-d$ ) and heart (panels $e, f$ ). In E10.0 Tie2CrePten ${ }^{+/+}$embryos, perivascular walls in both the yolk sac (panel $a$ ) and dorsal aorta (panel $c$ ) are lined with $\alpha-S_{M A}^{+}$PCs/vSMCs. (Panels $\left.b, d\right) \alpha S M A$ expression is dramatically reduced in E10.0 Tie2CrePten flox/flox embryos. (Panels $e, f$ ) Reductions in the sizes of $\alpha \mathrm{SMA}^{+}$cardiac muscle walls, the intraventricular septum, and cardiac trabeculae were also observed in Tie2CrePten flox/flox heart. (Panels $g, h$ ) Electron micrographs of E9.5 placentae reveal an absence of pericytes around the capillary network endothelium. (Blue arrows) Endothelial cells; (yellow arrows) blood cells in the vessel; (red arrows) pericytes.

the Tie2CrePten flox/flox vascular phenotype precedes the development of a functional circulation and the onset of growth retardation, these defects are most likely due to the Pten mutation and are not secondary to circulatory failure, ischemia, or growth retardation.

\section{Altered expression of VGFs in Tie2CrePten ${ }^{+/+}$ and Tie2CrePten ${ }^{\text {flox/flox }}$ mice}

RT-PCR analyses of gene expression in whole yolk sacs from E8.5 Tie2CrePten Th+ $^{+/}$and Tie2CrePten flox/flox embryos showed that a lack of Pten significantly reduced expression of connexin-40, Ang-1, ephrinB2, and VCAM1, but increased expression of Ang-2, VEGF-A, VEGFR1, VEGFR2, TGF- $\beta 1$, and PAI-1 (Fig. 4A). These differences were confirmed by RT-PCR analyses of VEGFR2 ${ }^{+}$cells from E9.5 Tie2CrePten ${ }^{+/+}$and Tie2CrePten flox/flox embryos (Fig. 4B), and by RT-PCR (Fig. 4C) and protein (Fig. $4 \mathrm{D}, \mathrm{E}$ ) analyses of human umbilical vein endothelial cells
(HUVECs) in which PTEN expression was reduced by siRNA. These results suggest that Pten deficiency leads directly to an altered VGF profile that may be responsible for the cardiovascular defects of Tie2CrePten ${ }^{\text {flox } / \text { flox }}$ mice.

In Tie2CrePten ${ }^{+/+}$MLECs, expression levels of VEGF-A and its receptors VEGFR1 and VEGFR2 were significantly increased after stimulation with VEGF-A, as expected. However, this expression was further increased in Tie2CrePten flox/+ MLECs (Fig. 4F). This enhanced expression of VEGF-A and its receptors may thus partly contribute to the enhanced angiogenesis observed in Tie2CrePten ${ }^{\text {flox/+ }}$ mice.

\section{Partial rescue of Tie2CrePten ${ }^{\text {flox/+ }}$ and Tie2CrePten ${ }^{\text {flox/flox }}$ mice by null mutation of $\mathrm{p} 110 \gamma$ or $\mathrm{p} 85 \alpha$}

$p 85 \alpha$ is the most abundant and widely expressed regulatory subunit of the class IA PI3Ks. These kinases are 

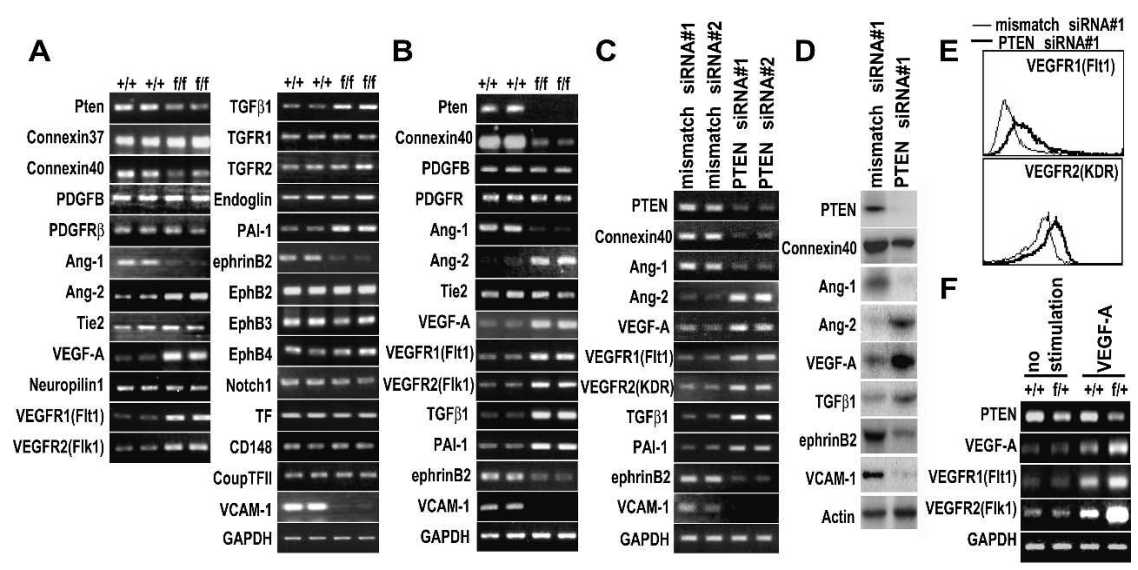

Figure 4. Expression of VGFs, VGF receptors, and their downstream molecules. RT-PCR and protein analyses of expression of the indicated molecules important for cardiovascular development are shown. (A) RT-PCR of whole wild type $(+/+)$ or Tie2CrePten ${ }^{\text {flox } / \text { flox }}(\mathrm{f} / \mathrm{f})$ yolk sacs at E8.5. (B) RT-PCR of VEGFR2 ${ }^{+}$cells from E9.5 $+/+$ or $\mathrm{f} / \mathrm{f}$ embryos. $(C-E)$ RT-PCR $(C)$, Western blotting $(D)$, and flow cytometry $(E)$ of HUVECs transfected with PTEN siRNA or mismatched control siRNA. Pten deficiency resulted in significantly reduced expression of connexin 40, Ang-1, ephrinB2, and VCAM-1 but significantly increased expression of Ang-2, VEGF-A, VEGFR1, VEGFR2, TGF- $\beta 1$, and PAI- $1 .|F|$ RT-PCR of VEGFR2 ${ }^{+}$cells from E9.5 Tie2CrePten $^{+/+}(+/+)$or Tie2CrePten ${ }^{\text {flox } /+}(\mathfrak{f} /+)$ embryos that had been left untreated or stimulated with VEGF-A for $24 \mathrm{~h}$. Pten heterozygosity in endothelial cells resulted in significantly increased expression of VEGF-A, VEGFR1, and VEGFR2. For $A-F$, data are representative of five independent experiments. GAPDH and actin served as loading controls.

activated following RTK engagement by VGFs. $p 110 \gamma$ is the sole catalytic subunit of the class IB PI3K that is activated by the $\beta \gamma$ subunit of $\mathrm{G}$ proteins. $p 110 \gamma$ thus acts downstream of activated GPCRs (Stoyanov et al. 1995; Dimmeler et al. 1998; Morales-Ruiz et al. 2001). We generated $p 85 \alpha^{-/-}$Tie2CrePten ${ }^{\text {flox } /+}$, p $85 \alpha^{-/-}$Tie2CrePten ${ }^{\text {flox } / \text { flox }}, \quad p 110 \gamma^{-/-}$Tie2CrePten ${ }^{\text {flox } /+}$, and $p 110 \gamma^{-/-}$Tie2CrePten ${ }^{\text {flox/flox }}$ double mutant mice to clarify the contribution of class IA and class IB PI3Ks to the phenotypes observed in Tie2CrePten ${ }^{\text {flox/+ }}$ and Tie2CrePten flox/flox mice. Unexpectedly, homozygous mutation of $p 110 \gamma$ partially restored control of angiogenic responses to $b \mathrm{FGF}, \quad b F G F+A n g-1$, and $b$ FGF + VEGF in Tie2CrePten flox/+ mice (Fig. 5A,B). Moreover, decreased tumor angiogenesis and tumor growth were observed in $p 110 \gamma^{-/-}$Tie2CrePten ${ }^{\text {flox } /+}$ double mutants after inoculation of either LLC cells (Fig. 5C,D) or B16BL6 cells (data not shown). We then analyzed whether the failure of cardiovascular development observed in Tie2CrePten flox/flox mice was also p110 $\gamma$-dependent. Homozygous loss of $p 110 \gamma$ led to a dramatic rescue of all Tie2CrePten flox/flox phenotypes (Fig. 5E,F) such that the double mutant mice survived until E18.5E19.5.

Homozygous mutation of $p 85 \alpha$ restored control of angiogenic responses in Tie2CrePten flox/+ mice to the same degree as mutation of $p 110 \gamma$ (Fig. 6A-D). However, the defect in cardiovascular morphogenesis seen in

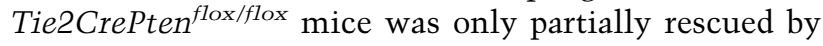
$p 85 \alpha$ deficiency (Fig. 6E) such that these animals survived only until E14.5-E15.5.

Our data show that the enhanced angiogenesis exhibited by Tie2CrePten flox $/+$ mice involves both $p 85 \alpha$ and $p 110 \gamma$, while the defect in cardiovascular morphogenesis in Tie2CrePten flox/flox mice depends more strongly on $p 110 \gamma$ than on $p 85 \alpha$. We conclude that the interaction of PI3Ks and Pten is essential for the regulation of cardiovascular morphogenesis and post-natal neovascularization, including tumor angiogenesis.

\section{Discussion \\ Heterozygous Pten deficiency in endothelial cells accelerates tumor growth by enhancing tumor angiogenesis}

Angiogenesis is a tightly regulated event critical for tumor growth. Tumor angiogenesis requires the activation, proliferation, and migration of endothelial cells, tube formation, and tissue infiltration by preexisting blood vessels. All these processes are controlled by angiogenic growth factors secreted either by the tumor or the surrounding stroma (Folkman and Shing 1992; Plate et al. 1994). Overexpression of VEGF, Ang-1, bFGF, and their receptors is strongly associated with invasion and metastasis in human cancers, and VGF inhibition blocks angiogenesis and tumor growth (Kim et al. 1993).

Our study is the first to demonstrate that the loss of Pten specifically in mouse endothelial cells makes them hypersensitive to VGFs and thus is responsible for enhanced angiogenesis leading accelerated tumor growth. An identical mechanism may be operating in humans with Cowden disease, a hereditary syndrome of cancer susceptibility caused by heterozygous mutations of PTEN. Our results have provided fresh insight into this syndrome and suggest that an individual who inherits a mutated PTEN allele is not only at risk for additional tumorigenic mutations due to the LOH of PTEN function but may also experience accelerated growth of any incipient tumors due to enhanced angiogenesis. Our findings thus further justify efforts to target PTEN and the PI3K-PKB/Akt pathway as a cancer therapy.

\section{Homozygous Pten deficiency in endothelial cells causes a fatal vascular remodeling defect}

The major downstream target of Pten is the survival kinase $\mathrm{PKB} / \mathrm{Akt}$, and $\mathrm{PKB} / \mathrm{Akt}$ overexpression supports endothelial cell survival in vitro (Gerber et al. 1998). Transient activation of $\mathrm{PI}$ K-PKB/Akt and subsequent acti- 
A

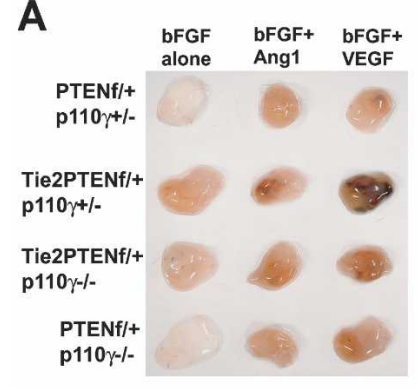

D

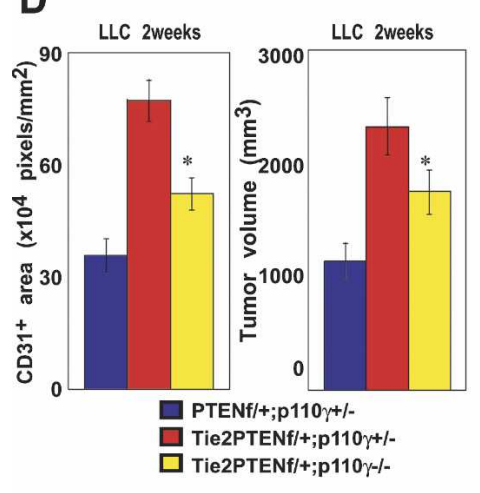

B

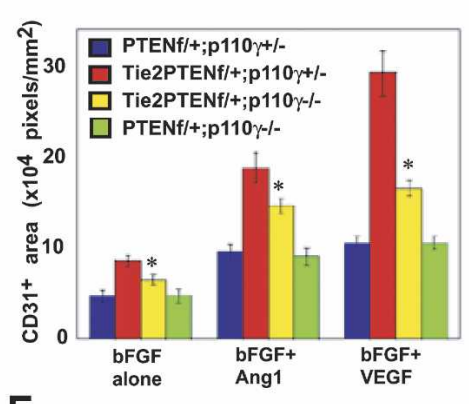

E PTENf/f Tie2PTENf/f Tie2PTENf/f

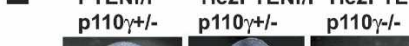

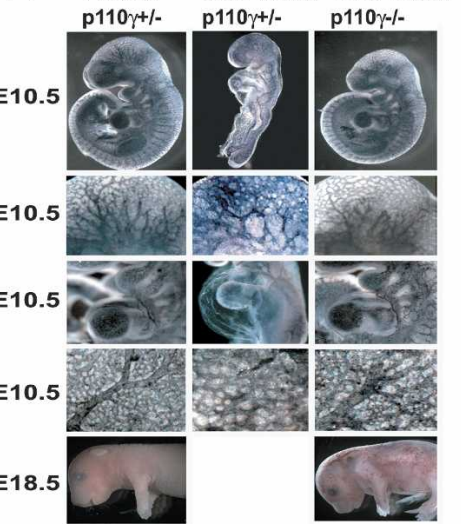

C

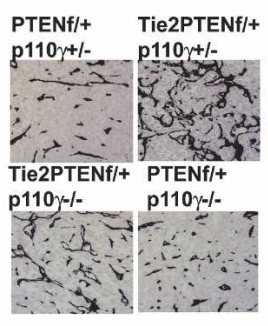

$\mathbf{F}$

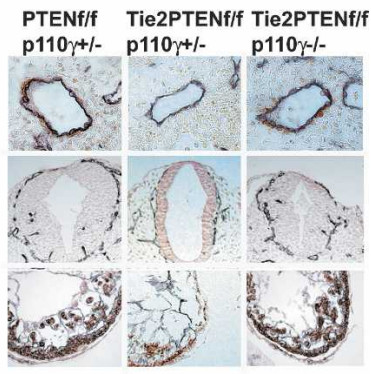

Figure 5. Partial rescue of Pten deficiency by $p 110 \gamma$ deficiency. $(A, B)$ Mitigation of increased angiogenesis driven by VGFs in $p 110 \gamma^{-/-}$Tie2CrePten ${ }^{\text {flox } /+}$ mice. (A) Representative photos of Matrigel plugs containing $b$ FGF, $b$ FGF + Ang- 1 , or $b$ FGF + VEGF-A. Plugs were removed from mice of the indicated genotypes at $14 \mathrm{~d}$ post-injection. $(B)$ Quantitated vascularization of the Matrigel plugs in $A$. p110 $\gamma$ deficiency significantly decreases the plug vascularization response $(n=6 /$ genotype). $(C, D)$ Mitigation of increased tumor growth. Shown are the results of anti-CD31 staining of sections of LLC tumors $(C)$, quantitated tumor vascularization $(D$, left panel), and tumor growth $(D$, right panel) at 2 wk post-LLC inoculation $(n=4 /$ genotype). Loss of $p 110 \gamma$ decreased the tumor vascularization and tumor volume observed in Tie2CrePten $\mathrm{flox}^{\text {fl+ }}$ mice. $(E, F)$. Partial restoration of cardiovascular development in $\mathrm{p}^{110 \gamma^{-/-} \text {Tie2CrePten }}{ }^{\text {flox } / \text { flox }}$ mice. Whole mounts stained with anti-CD31 antibody $(E)$, and histological sections stained with $\alpha$-SMA antibody $(F)$ show that loss of $p 110 \gamma$ dramatically rescues the growth retardation, vascular remodeling defect, reduction in vascular sprouting, enlarged pericardial cavity, and reduced thickness of the cardiac walls observed in Tie2CrePten flox/flox mice. For $B$ and $D$, quantitative results are expressed as the mean \pm SEM and are representative of three trials. Statistical differences were determined using the Student's $t$-test; $\left({ }^{\star}\right) p<0.05$.

vation of eNOS by growth factors such as VEGF enhance endothelial cell migration, angiogenesis, tube formation, and vasorelaxation (Shiojima and Walsh 2002). Constitutively active PKB/Akt (myrAkt) expression in vivo causes fatal vascular malformations and bleeding due to a failure in vascular remodeling (Sun et al. 2005). Mice deficient for Foxo1, a transcription factor negatively regulated by $\mathrm{PKB} / \mathrm{Akt}$, also show fatal vascular remodeling and cardiac defects (Furuyama et al. 2004). These findings are strikingly similar to those obtained for our endothelial cell-specific Pten-deficient mice. The phenotypes observed in Foxo1-deficient mice were attributed to reductions in connexin 37 , connexin 40 , and ephrinB2 expression (Furuyama et al. 2004). Indeed, we also found decreased connexin 40 and ephrinB2 expression in our mutants. Mice deficient for ephrinB2 die at E10.5 due to defects in vascular remodeling and sprouting that lead to pericardial effusion or bleeding (Wang et al. 1998). Taken together, these data suggest that dysregulation of downstream targets of PKB/Akt and Foxol due to loss of Pten function may be responsible for the lethal phenotype of Tie2CrePten ${ }^{\text {flox } / f l o x}$ mice.
The recruitment of PCs/vSMCs may determine the transition from an immature to a mature capillary network (Jain 2003) via a process regulated by factors such as PDGF (Lindahl et al. 1997), Ang-1 (Suri et al. 1996), and TGF- $\beta 1$ (Dickson et al. 1995). If the gene dosage of PDGF-B is reduced by half, a modest increase in acellular capillary formation occurs (Lindblom et al. 2003). However, both PDGF-B and its receptor PDGFR $\beta$ were normal in Tie2CrePten ${ }^{\text {flox/flox }}$ mice. Disruption of Ang-1 or its receptor Tie2 in knockout mice causes vascular defects due to impaired recruitment of PCs/vSMCs (Dumont et al. 1994; Suri et al. 1996). The effects of Ang-1 are antagonized by Ang-2 since Ang-2 inhibits the autophosphorylation of Tie2 induced by Ang-1 (Maisonpierre et al. 1997). Indeed, administration of Ang-2 causes a dose-dependent PC "dropout" in the normal retina (Hammes et al. 2004). In our mutant mice, Ang-2 expression was markedly increased while that of Ang-1 was reduced, perhaps explaining the impaired recruitment of PCs/vSMCs. Normally, the interaction of endothelial cells and PCs/vSMCs drives expression of TGF- $\beta 1$ (Antonelli-Orlidge et al. 1989). Mice lacking either TGF- 
A
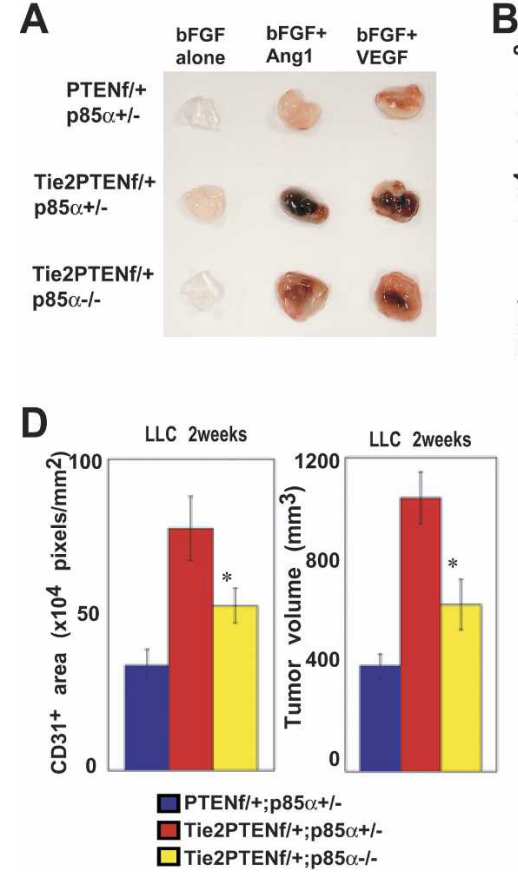

B

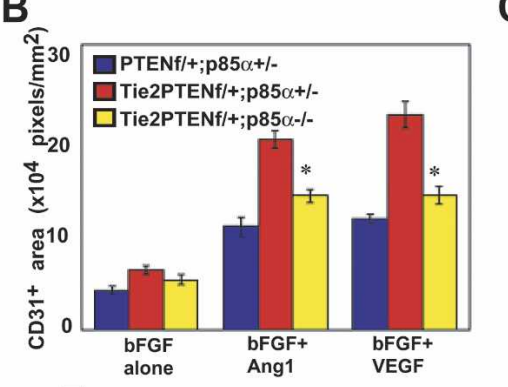

E PTENff/ Tie2PTENff Tie2PTENf/f

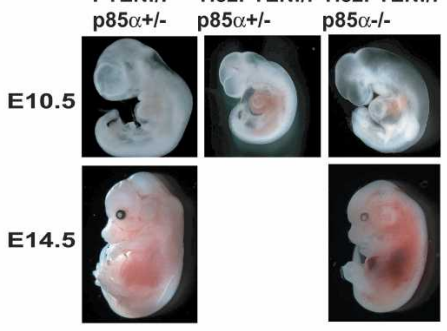

C

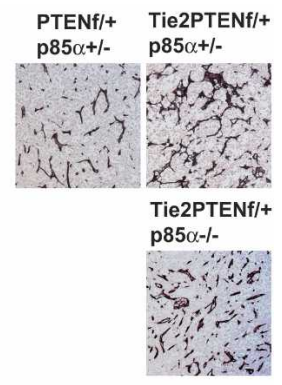

Figure 6. Partial rescue of Pten deficiency by $p 85 \alpha$ deficiency. $(A, B)$ Mitigation of increased angiogenesis driven by VGFs in $p 85 a^{-/-}$Tie2CrePten ${ }^{\text {flox/+ }}$ mice. (A) Representative photos of Matrigel plugs containing $b$ FGF, $b$ FGF + Ang- 1 , or $b$ FGF + VEGF-A. Plugs were removed from mice of the indicated genotypes at $14 \mathrm{~d}$ post-injection. (B) Quantitated vascularization of the Matrigel plugs in $A$. $p 85 \alpha$ deficiency significantly decreases the plug vascularization response ( $n=5 /$ genotype). $(C, D)$ Mitigation of increased tumor growth and tumor angiogenesis. Shown are the results of anti-CD31 staining of sections of LLC tumors $(C)$, quantitated tumor vascularization $(D$, left $)$, and tumor growth $(D$, right $)$ at 2 wk post-LLC inoculation $(n=4 /$ genotype $)$ Loss of $p 85 \alpha$ decreased the tumor vascularization and tumor volume observed in Tie2CrePten ${ }^{\text {flox } /+}$ mice. $(E)$ Whole mounts of E10.5 and E14.5 embryos of the indicated genotypes showed that loss of $\mathrm{p} 85 \alpha$ partially restored the development of Tie2CrePten flox/flox embryos. However, due to extensive bleeding, these embryos did not survive beyond E14.5-E15.5. For $B$ and $D$, quantitative results are expressed as the mean \pm SEM and are representative of four trials. Statistical differences were determined using the Student's $t$-test; $\left(^{\star}\right) p<0.05$.

$\beta 1$ or its receptor show abnormal capillary structure due to defective angiogenesis possibly associated with impaired PC/vSMC differentiation (Dickson et al. 1995; Larsson et al. 2001). However, TGF- $\beta 1$ was increased rather than decreased in our Tie2CrePten flox/flox mice. PKB/Akt activation inhibits Smad3, which eventually blocks TGF- $\beta$ signaling (Remy et al. 2004). However, when we examined the expression of PAI-1, a downstream target molecule widely used to detect TGF- $\beta$ activation, it was clear that such a mechanism was not operating in Pten-deficient endothelial cells at midgestation.

VEGF is a multifunctional VGF that stimulates the migration, proliferation, and survival of endothelial cells and promotes microvascular permeability and angiogenesis. VEGF also recruits PCs to the endothelial plexus (Benjamin et al. 1998). The expression of VEGF-A and its receptors was increased in Tie2CrePten ${ }^{\text {flox/flox }}$ mice, consistent with a previous report in which activation of the PI3K pathway led to augmented VEGF-A expression (Jiang et al. 2000). Increased VEGF expression during lung organogenesis overstimulates endothelial cell growth and leads to abnormally large capillaries (Zeng et al. 1998). Mice overexpressing VEGF die at E14 due to cardiac abnormalities (Miquerol et al. 2000). We specu- late that the Pten deficiency in our homozygous mutant mice contributed to increased VEGF signaling, leading to large capillary lumens with increased numbers of endothelial cells as well as a thin myocardium in the heart.

VCAM-1 signaling is also important for cardiovascular development, and VCAM-1 deficiency causes pericardial bleeding and impaired cardiomyocyte development (Kwee et al. 1995). The dramatic reduction of VCAM-1 expression in Tie2CrePten flox/flox embryos might partially explain their cardiac phenotypes. Defects in additional VGFs, their receptors, or cell adhesion molecules acting downstream of PI3K and PKB/Akt may also contribute to the cardiovascular defect.

Pten is deleted only in the endocardium and not in the myocardium of Tie2CrePten ${ }^{\text {flox/flox }}$ mice. However, Tie2CrePten flox/flox mice showed a thin myocardial layer, in contrast to the well-developed trabecular folds observed in myocardium-specific Pten-deficient mice (Crackower et al. 2002). We speculate that this discrepancy arises because the abnormal endocardium of Tie2CrePten ${ }^{\text {flox/flox }}$ mice cannot provide the appropriate inductive interactions for proper development of the underlying myocardium (Suri et al. 1996). 
Mutation of $\mathrm{p} 85 \alpha$ or $\mathrm{p} 110 \gamma$ partially rescues endothelial cell-specific Pten defects

The precise functions of PI3K isoforms in endothelial cells have been difficult to ascertain. Because most VGF receptors have tyrosine kinase activity, class IA PI3Ks likely play major roles in cardiovasculogenesis and tumor angiogenesis. Indeed, endothelial cell growth/survival and angiogenesis are enhanced following ectopic expression of constitutively active $p 110 \alpha$, the catalytic subunit of class IA PI3Ks (Jiang et al. 2000). Consistent with this finding, the enhanced angiogenesis and accelerated tumor growth observed in our Tie2CrePten ${ }^{\text {flox/+ }}$ mice, and the impaired cardiovascular morphogenesis observed in our Tie2CrePten flox/flox mice were partially resolved by loss of $p 85 \alpha$, the major regulatory subunit of class IA PI3Ks.

In this study, we shed light on the potential roles of the class IB PI3K in cardiovascular morphogenesis and post-natal angiogenesis. We generated double mutant mice lacking both Pten and class IB PI3K functions and demonstrated that the post-natal angiogenic responses of Tie2CrePten ${ }^{\text {flox/+ }}$ mice were rescued to the same degree by loss of $p 110 \gamma$, the catalytic subunit of $\mathrm{PI} 3 \mathrm{~K} \gamma$, as by loss of $p 85 \alpha$. Furthermore, compared with $p 85 \alpha$ deficiency, $p 110 \gamma$ deficiency dramatically resolved the defective cardiovasculogenesis observed in Tie2CrePten ${ }^{\text {flox/flox }}$ mice. In the $p 85 \alpha$-deficient mice used in this study, only the $\mathrm{p} 85 \alpha$ isoform was deleted, not its alternative splicing isoforms $\mathrm{p} 55 \alpha$ and $\mathrm{p} 50 \alpha$. Moreover, $p 85 \beta$ and $p 55 \gamma$, the alternative regulatory subunits of class IA PI3Ks, still exist in these mice. However, since $p 85 \alpha$ is the major regulatory subunit of class IA PI3Ks, we believe that the class IB PI3K may have a more important function in cardiovasculogenesis than do the class IA PI3Ks.

We did not expect the enhanced angiogenesis induced in Tie2CrePten flox/+ mice by RTK agonists (e.g., VEGF and Ang-1) to be partially rescued by $p 110 \gamma$ deficiency. Up until now, $p 110 \gamma$ has been postulated to be activated downstream of GPCR but not downstream of RTK. Indeed, the activation of PKB/Akt and MAPK induced by VEGF and Ang-1 was not suppressed by $p 110 \gamma$ deficiency in vitro (Supplementary Fig. 4A). It is thus unlikely that an RTK type VGF receptor directly couples with p110y, an interaction noted for PDGF receptors and erythropoietin receptors (Kaplan-Albuquerque et al. 2003). It may be that, in vivo, an unknown VGF (possibly a GPCR ligand) activates p110 $\gamma$ and influences RTK signaling that is initiated by VEGF or Ang-1 and leads to angiogenesis. In endothelial cells, identified GPCR ligands include sphingosine-1-phosphate $(\mathrm{S} 1 \mathrm{P})$, angiotensin II, CXCL-16, and shear stress (Stoyanov et al. 1995; Dimmeler et al. 1998). One of the candidate GPCR ligands that may activate p110y in endothelial cells is S1P. S1P induces endothelial cell proliferation, migration, and morphogenesis in vitro and in vivo (Lee et al. 1999). Moreover, EDG1, a GPCR-type S1P receptor, is essential for vascular maturation (Liu et al. 2000). We have shown here that $p 110 \gamma$ deficiency partially blocks enhanced angiogenesis driven not only by Ang-1 or VEGF-A but also by S1P (Supplementary Fig. 4B). However, S1P-induced activation of $\mathrm{PKB} / \mathrm{Akt}$ and MAPK was not suppressed by p110 $\gamma$ deficiency (Supplementary Fig. 4A), indicating that the major downstream target of S1P may not be p110\%.

Although PTEN has dual lipid and protein phosphatase activities (Maehama and Dixon 1998; Li and Sun 1997), our results clearly demonstrate that a primary function of PTEN is to fine-tune the intracellular level of PIP3 produced by PI3Ks and thereby regulate vascular remodeling and tumor angiogenesis. Our data also suggest the functional overlapping of class IA and IB PI3Ks in angiogenesis. This hypothesis is supported by the lack of an endothelial cell phenotype in mice lacking $p 85 \alpha$ (Fruman et al. 1999; Terauchi et al. 1999), $p 85 \beta$ (Ueki et

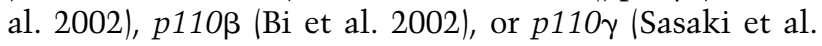
2000) or in $p 110 \delta$ "kinase dead" knock-in mice (Okkenhaug et al. 2002). Furthermore, our results demonstrate that, among the multiple PIP3 phosphatases, PTEN has an exclusive role in down-regulating PIP3 in endothelial cells. Various PI3K $\gamma$-specific inhibitors that are under investigation as anti-inflammatory drugs may therefore also be useful as cancer therapies targeting tumor angiogenesis.

Our study is the first report of the functional analysis of Pten and PI3K $\gamma$ in murine endothelial cells in vivo. We have demonstrated that the normal function of the $\mathrm{PI}$ K-PKB/Akt-Pten pathway in endothelial cells is required for cardiovascular development, and that loss of Pten-mediated control of this pathway enhances tumor angiogenesis. Deficiency in Pten function thus contributes both to susceptibility to new tumorigenic mutations and to accelerated tumor growth. Inhibition of the PI3K pathway, including $\mathrm{PI} 3 \mathrm{~K} \gamma$, is thus an attractive therapeutic target for the treatment of various malignancies.

\section{Materials and methods}

\section{Generation of mutant mice}

Pten $^{\text {flox/flox }}$ mice (C57BL6/J background), generated as previously described (Suzuki et al. 2001), were mated to Tie2Cre transgenic mice (C57BL6/J background) (Koni et al. 2001), in which expression of Cre is controlled by the Tie2 promoter. Tie2 is strongly activated in endothelial cells. Male Pten ${ }^{\text {flox/flox }}$ mice were crossed with female Tie2CrePten ${ }^{\text {flox/+ }}$ mice to avoid the ectopic recombination observed when the Tie2Cre locus is transmitted from male mice. Offspring carrying Tie2Cre and two copies of the floxed Pten allele (Tie2CrePten ${ }^{\text {flox/flox }}$ ), Tie2Cre plus one copy of the floxed Pten allele (Tie2CrePten ${ }^{\text {flox } /+}$ ), and Tie2Cre plus two copies of the wild-type Pten allele (Tie2CrePten $\left.{ }^{++}\right)$were used in analyses as homozygous mutant (Tie2CrePten ${ }^{\text {flox/flox}}$ ), heterozygous mutant (Tie2CrePten $\left.{ }^{f l o x /+}\right)$, and wild-type $\left(\right.$ Tie2CrePten $^{+/+}$) mice, respectively. p110 ${ }^{-/-}$Tie2CrePten ${ }^{\text {flox/flox }}$ and $p 85 \alpha^{-/-}$Tie2CrePten ${ }^{\text {flox } / \text { flox }}$ double mutant mice were generated by crossing male $p 110 \gamma^{-/-}$(C57BL6/J background) (Sasaki et al. 2000) or $p 85 \alpha^{-/-}$mice (C57BL6/J background) (Terauchi et al. 1999) with female Tie2CrePten flox/+ mice, followed by the crossing of male $p 110 \gamma^{-/}$Pten flox/flox or $p 85 \alpha^{-/-}$Pten ${ }^{\text {flox } / \text { flox }}$ mice with female $p 110 \gamma^{+/-}$Tie2CrePten ${ }^{\text {flox } /+}$ or $p 85 \alpha^{+/-}$Tie2CrePten ${ }^{\text {flox } /+}$ mice, respectively. 
Homologous recombination was detected using a GFP reporter gene as described previously (Kawamoto et al. 2000). Briefly, the reporter transgene contains the CAG promoter, the loxP-flanked CAT gene with an SV40 polyadenylation signal,

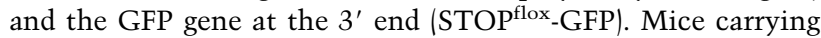
both the Tie2Cre and STOP flox $-G F P$ transgenes were generated to identify cells in which recombination had occurred. Flk-LacZ knock-in mutant mice have been described previously (Yamaguchi et al. 1993). Interbreeding of Tie2CrePten ${ }^{\text {flox } /+}$ and Flk-LacZ heterozygous mutant mice generated Pten homozygous and Flk-LacZ heterozygous double mutant mice. Littermate embryos were used for all experiments. The Institutional Review Board of the Akita University School of Medicine approved all animal experiments.

\section{PCR analysis of Pten genotypes}

Genomic DNA from mouse tails was isolated and amplified by PCR as described (Suzuki et al. 2001). Sequences of sense and anti-sense primers for floxed and wild-type Pten alleles and the Tie2Cre transgene are listed in Supplementary Table 1. Amplified fragments of $705 \mathrm{bp}$ ( $\Delta$ Pten), $514 \mathrm{bp}$ (floxed Pten), $428 \mathrm{bp}$ (wild-type Pten), and 269 bp (Tie2Cre transgene) were obtained.

\section{$R T-P C R$}

To assay VGF expression, RNA from $10^{4}$ cells was extracted using an RNeasy Mini kit (Qiagen, Inc.) and reverse transcribed using an Advantage RT-for-PCR Kit (Clontech). Sequences of specific primers and amplified product sizes are listed in Supplementary Table 1.

\section{Matrigel plug assays}

Matrigel plug assays were performed as described previously (Prewett et al. 1999). Six-week-old mice were injected subcutaneously at the abdominal midline with $0.5 \mathrm{~mL}$ Matrigel (BD Biosciences) supplemented with $250 \mathrm{ng} b$ FGF (R\&D Systems) and/or 5 ng VEGF-A (VEGF165; PeproTech EC Ltd.) and/or 150 ng Ang-1 (provided by G.Y. Koh, KAIST, Deajeon, Korea). Control mice were injected with PBS-Matrigel. Mice were sacrificed $14 \mathrm{~d}$ after Matrigel injection, and vascularization was quantitated by immunohistological examination using anti-PECAM1/CD31 antibody (Pharmingen) and a horseradish peroxidaseconjugated anti-rat Ig secondary antibody (Biosource International). Samples were then incubated with PBS containing 0.3 $\mathrm{mg} / \mathrm{mL}$ diaminobenzidine (Dojin Laboratories) in the presence of $0.05 \% \mathrm{NiCl}_{2}$ for $10-30 \mathrm{~min}$ at room temperature, followed by the addition of $0.01 \%$ hydrogen peroxide. Infiltration of capillaries into the Matrigel was visualized by anti-CD31 staining and quantitated using NIH image software.

\section{Tumor formation assay}

The tumorigenicity of murine LLC cells or B16-BL6 melanoma cells was assayed by injecting $2 \times 10^{5}$ cells subcutaneously into the backs of 8 -wk-old Tie2CrePten ${ }^{+/+}$and Tie2CrePten ${ }^{\text {flox } /+}$ mice. After $14 \mathrm{~d}$ (LCC) or $21 \mathrm{~d}$ (B16-BL6), tumor diameters were measured using calipers. Tumor diameter was converted to tumor volume using the calculation: volume $=4 / 3 \pi r^{3}$.

\section{Isolation of MLECS}

MLECs of Tie2CrePten ${ }^{+/+}$and Tie2CrePten ${ }^{\text {flox/+ }}$ mice were prepared as previously described (Hartwell et al. 1998). Briefly, lung tissues were excised, digested with $0.1 \%$ collagenase A (Sigma), and disaggregated by nylon-mesh to produce a single suspension. This mixed population was negatively selected with antiCD16 mAb (Pharmingen), positively selected with anti-ICAM-2
$\mathrm{mAb}$ (Pharmingen), and purified using anti-IgG-coated magnetic beads (Dynal Biotech). The endothelial cell population was $>90 \%$ pure as assessed by anti-CD31 staining. MLECs were grown on a $1 \%$ gelatin-coated dish in Ham's F-12 medium supplemented with $20 \%$ FBS, $0.2 \mathrm{U} / \mathrm{mL}$ heparin, and endothelial mitogen (Biomedical Technologies) (Hartwell et al. 1998).

\section{Cell proliferation and transmigration assays}

Cell proliferation in response to $24 \mathrm{~h}$ stimulation with Ang-1 (300 ng/mL) or VEGF-A (10 ng/mL) was evaluated by PCNA immunostaining as previously described (Zhang et al. 2004). Cell transmigration assays were performed as described (Ito et al. 2003) using MLECs from 8-10-wk-old Tie2CrePten ${ }^{+/+}$and Tie2CrePten ${ }^{\text {flox } /+}$ mice. Migration was measured $4 \mathrm{~h}$ after the addition of Ang-1 (300 ng/mL) or VEGF-A (10 ng/mL) to the lower chamber of a Transwell.

\section{Whole-mount embryo immunostaining and LacZ staining}

Immunostaining was conducted using anti-CD31 antibody or anti-smooth muscle actin antibody (1A4; Dako Cytomation). For LacZ staining, embryos and yolk sacs were fixed in cold $4 \%$ paraformaldehyde in PBS for 10 min, rinsed twice with PBS, and stained from $2 \mathrm{~h}$ to overnight at $37^{\circ} \mathrm{C}$ in X-Gal buffer $15 \mathrm{mM}$ potassium ferrocyanide, $5 \mathrm{mM}$ potassium ferricyanide, $2 \mathrm{mM}$ $\mathrm{MgCl}_{2}$, and $1 \mathrm{mg} / \mathrm{mL} \mathrm{X}-\mathrm{Gal}$ in PBS at $\mathrm{pH}$ 7.2).

\section{Electron microscopy}

The placentae and yolk sacs of E9.5 embryos were isolated, washed with washing buffer $(3.5 \%$ sucrose in $0.1 \mathrm{M}$ sodium cacodylate buffer at $\mathrm{pH} 7.3$ ), post-fixed in buffered osmium tetroxide, and embedded in epoxy according to standard procedures. Ultrathin sections were stained in uranyl acetate and lead citrate and examined using a 100CX electron microscope operated at $60 \mathrm{kV}$ (JEOL)

\section{Cell culture and siRNA transfection}

Primary HUVECs (Clonetics Corp.) were grown in the EGM-2 Bullet kit (Clonetics) containing FBS and supplemental growth factors. HUVECs $\left(5 \times 10^{4}\right.$ cells/well) were cultured in 24-well plates, and transfections were performed using Lipofectamine 2000 (Invitrogen) according to the manufacturer's protocol. Lipofectamine $2000(2 \mu \mathrm{L})$ and $0.2 \mu \mathrm{g}$ siRNA was used for each transfection. Sequences of siRNAs corresponded to nucleotides 1081-1105 or 1053-1077 of human PTEN (GenBank accession no. NM 000314) or were mismatched siRNAs: PTENsiRNA\#1, 5'-AAGAGGAUGGAUUCGACUUAGACUU-3'; PTENsiRNA\#2, 5'-AUCGUUAGCAGAAACAAAAGGAGAU-3'; control mismatch siRNA\#1, 5'-AAGAGGAUGGUAUCGACUUAGACUU-3'; and control mismatch siRNA\#2, 5'-AUCGUGAGCACAAA GAAAAUGAGAU-3'. RNA duplexes (25 nucleotides) with AG overhangs (sense) and AU overhangs (anti-sense) at both $3^{\prime}$-ends were prepared as described (Miyagishi and Taira 2002).

\section{Western blotting}

Total cell lysates $(30 \mu \mathrm{g})$ were analyzed by Western blotting using the following antibodies: anti-human PTEN /Cascade Bioscience); antibodies against connexin 40, Ang-1, Ang-2, VEGF-A, TGF- $\beta$, ephrinB2, VCAM-1, or actin (all from Santa Cruz Biotechnology); anti-VEGFR1 (R\&D Systems); and antiVEGFR2 (Kyowa Hakko). For assays involving Tie2CrePten ${ }^{\text {flox } /+}$ MLECs, VEGF-A (10 ng/mL) was added for $24 \mathrm{~h}$ prior to lysate preparation. 


\section{Flow cytometric analysis}

HUVECs were preincubated with anti-CD16 mAb to minimize nonspecific staining. Cells were then stained with PE-conjugated anti-VEGFR1 (R\&D Systems) or anti-VEGFR2 (Kyowa Hakko), followed by FITC-conjugated anti-mouse IgG (Becton Dickinson). Flow cytometric analysis was performed using a FACSCalibur with CELLQuest software (Becton Dickinson).

\section{Acknowledgments}

We thank Dr. Shigeo Koyasu and Dr. Yuichi Oike (Keio University); Dr. Tetsuo Noda and Dr. Noriko Ohsumi (Tohoku University); Dr. Shin Yonehara (Kyoto University); Dr. Nobuyuki Takakura (Kanazawa University); and Dr. Shunsuke Takasuga, Ms. Motoka Yamada, Ms. Naoko Baba, Ms. Yuki Sakamoto, and Mr. Akihiko Tomita (Akita University) for helpful discussions and technical support. We also thank Dr. Shigeo Koyasu (Keio University), Dr. Janet Rossant (Samuel Lunenfeld Research Institute, Toronto), and Dr. Irmgard Forster (Institute for Medical Microbiology, Immunology, and Hygiene, Munich) for providing the $p 85 \alpha^{-/-}$, Flk-LacZ knock-in mutant mice, and LysMCre transgenic mice, respectively. This work was supported by grants from the Ministry of Education, Science, Sports and Culture, Japan; the Daiwa Securities Health Foundation; the Osaka Cancer Research Foundation; the Japanese Heart Foundation; the Takeda Science Foundation; the Uehara Memorial Foundation; and the Yamanouchi Foundation for Research on Metabolic Disorders.

\section{References}

Antonelli-Orlidge, A., Saunders, K.B., Smith, S.R., and D'Amore, P.A. 1989. An activated form of transforming growth factor $\beta$ is produced by cocultures of endothelial cells and pericytes. Proc. Natl. Acad. Sci. 86: 4544-4548.

Benjamin, L.E., Hemo, I., and Keshet, E. 1998. A plasticity window for blood vessel remodelling is defined by pericyte coverage of the preformed endothelial network and is regulated by PDGF-B and VEGF. Development 125: 1591-1598.

Bi, L., Okabe, I., Bernard, D.J., and Nussbaum, R.L. 2002. Early embryonic lethality in mice deficient in the p110 3 catalytic subunit of PI 3-kinase. Mamm. Genome 13: 169-172.

Bingle, L., Brown, N.J., and Lewis, C.E. 2002. The role of tumour-associated macrophages in tumour progression: Implications for new anticancer therapies. J. Pathol. 196: 254-265.

Crackower, M.A., Oudit, G.Y., Kozieradzki, I., Sarao, R., Sun, H., Sasaki, T., Hirsch, E., Suzuki, A., Shioi, T., Irie-Sasaki, J., et al. 2002. Regulation of myocardial contractility and cell size by distinct PI3K-PTEN signaling pathways. Cell 110: 737-749.

Daniel, T.O. and Abrahamson, D. 2000. Endothelial signal integration in vascular assembly. Annu. Rev. Physiol. 62: 649671.

Dickson, M.C., Martin, J.S., Cousins, F.M., Kulkarni, A.B., Karlsson, S., and Akhurst, R.J. 1995. Defective haematopoiesis and vasculogenesis in transforming growth factor- $\beta 1$ knock out mice. Development 121: 1845-1854.

Dimmeler, S., Assmus, B., Hermann, C., Haendeler, J., and Zeiherk, A.M. 1998. Fluid shear stress stimulates phosphorylation of Akt in human endothelial cells: Involvement in suppression of apoptosis. Circ. Res. 83: 334-341.

Dumont, D.J., Gradwohl, G., Fong, G.H., Puri, M.C., Gertsenstein, M., Auerbach, A., and Breitman, M.L. 1994. Dominant-negative and targeted null mutations in the endothelial receptor tyrosine kinase, tek, reveal a critical role in vasculogenesis of the embryo. Genes \& Dev. 8: 1897-1909.
Folkman, J. and Shing, Y. 1992. Angiogenesis. J. Biol. Chem. 267: 10931-10934.

Fruman, D.A., Snapper, S.B., Yballe, C.M., Davidson, L., Yu, J.Y., Alt, F.W., and Cantley, L.C. 1999. Impaired B cell development and proliferation in absence of phosphoinositide 3-kinase p85 $\alpha$. Science 283: 393-397.

Furuyama, T., Kitayama, K., Shimoda, Y., Ogawa, M., Sone, K., Yoshida-Araki, K., Hisatsune, H., Nishikawa, S., Nakayama, K., Ikeda, K., et al. 2004. Abnormal angiogenesis in Foxol (Fkhr)-deficient mice. J. Biol. Chem. 279: 34741-34749.

Gerber, H.P., McMurtrey, A., Kowalski, J., Yan, M., Keyt, B.A., Dixit, V., and Ferrara, N. 1998. Vascular endothelial growth factor regulates endothelial cell survival through the phosphatidylinositol 3'-kinase/Akt signal transduction pathway: Requirement for Flk-1/KDR activation. J. Biol. Chem. 273: 30336-30343.

Hammes, H.P., Lin, J., Wagner, P., Feng, Y., Vom Hagen, F., Krzizok, T., Renner, O., Breier, G., Brownlee, M., and Deutsch, U. 2004. Angiopoietin-2 causes pericyte dropout in the normal retina: Evidence for involvement in diabetic retinopathy. Diabetes 53: 1104-1110.

Hartwell, D.W., Mayadas, T.N., Berger, G., Frenette, P.S., Rayburn, H., Hynes, R.O., and Wagner, D.D. 1998. Role of P-selectin cytoplasmic domain in granular targeting in vivo and in early inflammatory responses. J. Cell Biol. 143: 1129-1141.

Hellstrom, M., Gerhardt, H., Kalen, M., Li, X., Eriksson, U., Wolburg, H., and Betsholtz, C. 2001. Lack of pericytes leads to endothelial hyperplasia and abnormal vascular morphogenesis. J. Cell Biol. 153: 543-553.

Huang, J. and Kontos, C.D. 2002. PTEN modulates vascular endothelial growth factor-mediated signaling and angiogenic effects. J, Biol. Chem. 277: 10760-10766.

Hungerford, J.E. and Little, C.D. 1999. Developmental biology of the vascular smooth muscle cell: Building a multilayered vessel wall. J. Vasc. Res. 36: 2-27.

Ito, Y., Oike, Y., Yasunaga, K., Hamada, K., Miyata, K., Matsumoto, S., Sugano, S., Tanihara, H., Masuho, Y., and Suda, T. 2003. Inhibition of angiogenesis and vascular leakiness by angiopoietin-related protein 4. Cancer Res. 63: 6651-6657.

Jain, R.K. 2003. Molecular regulation of vessel maturation. Nat. Med. 9: 685-693.

Jiang, B.H., Zheng, J.Z., Aoki, M., and Vogt, P.K. 2000. Phosphatidylinositol 3-kinase signaling mediates angiogenesis and expression of vascular endothelial growth factor in endothelial cells. Proc. Natl. Acad. Sci. 97: 1749-1753.

Kaplan-Albuquerque, N., Garat, C., Desseva, C., Jones, P.L., and Nemenoff, R.A. 2003. Platelet-derived growth factor-BB-mediated activation of Akt suppresses smooth muscle-specific gene expression through inhibition of mitogen-activated protein kinase and redistribution of serum response factor. $J$. Biol. Chem. 278: 39830-39838.

Kawamoto, S., Niwa, H., Tashiro, F., Sano, S., Kondoh, G., Takeda, J., Tabayashi, K., and Miyazaki, J. 2000. A novel reporter mouse strain that expresses enhanced green fluorescent protein upon Cre-mediated recombination. FEBS Lett. 470: 263-268.

Kim, K.J., Li, B., Winer, J., Armanini, M., Gillett, N., Phillips, H.S., and Ferrara, N. 1993. Inhibition of vascular endothelial growth factor-induced angiogenesis suppresses tumour growth in vivo. Nature 362: 841-844.

Koni, P.A., Joshi, S.K., Temann, U.A., Olson, D., Burkly, L., and Flavell, R.A. 2001. Conditional vascular cell adhesion molecule 1 deletion in mice: Impaired lymphocyte migration to bone marrow. J. Exp. Med. 193: 741-754.

Kwee, L., Baldwin, H.S., Shen, H.M., Stewart, C.L., Buck, C., Buck, C.A., and Labow, M.A. 1995. Defective development of the embryonic and extraembryonic circulatory systems in 
vascular cell adhesion molecule (VCAM-1) deficient mice. Development 121: 489-503.

Larsson, J., Goumans, M.J., Sjostrand, L.J., van Rooijen, M.A., Ward, D., Leveen, P., Xu, X., ten Dijke, P., Mummery, C.L., and Karlsson, S. 2001. Abnormal angiogenesis but intact hematopoietic potential in TGF- $\beta$ type I receptor-deficient mice. $E M B O$ J. 20: 1663-1673.

Lee, M.J., Thangada, S., Claffey, K.P., Ancellin, N., Liu, C.H., Kluk, M., Volpi, M., Sha'afi, R.I., and Hla, T. 1999. Vascular endothelial cell adherens junction assembly and morphogenesis induced by sphingosine-1-phosphate. Cell 99: 301-312.

Li, D.M. and Sun, H. 1997. TEP1, encoded by a candidate tumor suppressor locus, is a novel protein tyrosine phosphatase regulated by transforming growth factor $\beta$. Cancer Res. 57: 2124-2129.

Li, J., Yen, C., Liaw, D., Podsypanina, K., Bose, S., Wang, S.I., Puc, J., Miliaresis, C., Rodgers, L., McCombie, R., et al. 1997. PTEN: A putative protein tyrosine phosphatase gene mutated in human brain, breast, and prostate cancer. Science 275: 1943-1947.

Liaw, D., Marsh, D.J., Li, J., Dahia, P.L., Wang, S.I., Zheng, Z., Bose, S., Call, K.M., Tsou, H.C., Peacocke, M., et al. 1997. Germline mutations of the PTEN gene in Cowden disease: An inherited breast and thyroid cancer syndrome. Nat. Genet. 16: 64-67.

Lindahl, P., Johansson, B.R., Leveen, P., and Betsholtz, C. 1997. Pericyte loss and microaneurysm formation in PDGF-B-deficient mice. Science 277: 242-245.

Lindblom, P., Gerhardt, H., Liebner, S., Abramsson, A., Enge, M., Hellstrom, M., Backstrom, G., Fredriksson, S., Landegren, U., Nystrom, H.C., et al. 2003. Endothelial PDGF-B retention is required for proper investment of pericytes in the microvessel wall. Genes \& Dev. 17: 1835-1840.

Liu, Y., Wada, R., Yamashita, T., Mi, Y., Deng, C.X., Hobson, J.P., Rosenfeldt, H.M., Nava, V.E., Chae, S.S., Lee, M.J., et al. 2000. Edg-1, the G protein-coupled receptor for sphingosine1-phosphate, is essential for vascular maturation. J. Clin. Invest. 106: 951-961.

Maehama, T. and Dixon, J.E. 1998. The tumor suppressor, PTEN/MMAC1, dephosphorylates the lipid second messenger, phosphatidylinositol 3,4,5-trisphosphate. J. Biol. Chem. 273: $13375-13378$.

Maisonpierre, P.C., Suri, C., Jones, P.F., Bartunkova, S., Wiegand, S.J., Radziejewski, C., Compton, D., McClain, J., Aldrich, T.H., Papadopoulos, N., et al. 1997. Angiopoietin-2, a natural antagonist for Tie2 that disrupts in vivo angiogenesis. Science 277: 55-60.

Miquerol, L., Langille, B.L., and Nagy, A. 2000. Embryonic development is disrupted by modest increases in vascular endothelial growth factor gene expression. Development 127: 3941-3946.

Miyagishi, M. and Taira, K. 2002. U6 promoter-driven siRNAs with four uridine $3^{\prime}$ overhangs efficiently suppress targeted gene expression in mammalian cells. Nat. Biotechnol. 20: 497-500.

Morales-Ruiz, M., Lee, M.J., Zollner, S., Gratton, J.P., Scotland, R., Shiojima, I., Walsh, K., Hla, T., and Sessa, W.C. 2001. Sphingosine 1-phosphate activates Akt, nitric oxide production, and chemotaxis through a Gi protein/phosphoinositide 3-kinase pathway in endothelial cells. J. Biol. Chem. 276: 19672-19677.

Okkenhaug, K., Bilancio, A., Farjot, G., Priddle, H., Sancho, S., Peskett, E., Pearce, W., Meek, S.E., Salpekar, A., Waterfield, M.D., et al. 2002. Impaired B and T cell antigen receptor signaling in p110s PI 3-kinase mutant mice. Science 297: 1031-1034.
Plate, K.H., Breier, G., and Risau, W. 1994. Molecular mechanisms of developmental and tumor angiogenesis. Brain Pathol. 4: 207-218.

Prewett, M., Huber, J., Li, Y., Santiago, A., O'Connor, W., King, K., Overholser, J., Hooper, A., Pytowski, B., Witte, L., et al. 1999. Antivascular endothelial growth factor receptor (fetal liver kinase 1) monoclonal antibody inhibits tumor angiogenesis and growth of several mouse and human tumors. Cancer Res. 59: 5209-5218.

Remy, I., Montmarquette, A., and Michnick, S.W. 2004. PKB/ Akt modulates TGF- $\beta$ signalling through a direct interaction with Smad3. Nat. Cell Biol. 6: 358-365.

Sasaki, T., Irie-Sasaki, J., Jones, R.G., Oliveira-dos-Santos, A.J., Stanford, W.L., Bolon, B., Wakeham, A., Itie, A., Bouchard, D., Kozieradzki, I., et al. 2000. Function of PI3Kgamma in thymocyte development, $\mathrm{T}$ cell activation, and neutrophil migration. Science 287: 1040-1046.

Shiojima, I. and Walsh, K. 2002. Role of Akt signaling in vascular homeostasis and angiogenesis. Circ. Res. 90: 1243-1250.

Stoyanov, B., Volinia, S., Hanck, T., Rubio, I., Loubtchenkov, M., Malek, D., Stoyanova, S., Vanhaesebroeck, B., Dhand, R., Nurnberg, B., et al. 1995. Cloning and characterization of a G protein-activated human phosphoinositide-3 kinase. Science 269: 690-693.

Su, J.D., Mayo, L.D., Donner, D.B., and Durden, D.L. 2003. PTEN and phosphatidylinositol 3 '-kinase inhibitors upregulate p53 and block tumor-induced angiogenesis: Evidence for an effect on the tumor and endothelial compartment. Cancer Res. 63: 3585-3592.

Sun, J.F., Phung, T., Shiojima, I., Felske, T., Upalakalin, J.N., Feng, D., Kornaga, T., Dor, T., Dvorak, A.M., Walsh, K., et al. 2005. Microvascular patterning is controlled by fine-tuning the Akt signal. Proc. Natl. Acad. Sci. 102: 128-133.

Suri, C., Jones, P.F., Patan, S., Bartunkova, S., Maisonpierre, P.C., Davis, S., Sato, T.N., and Yancopoulos, G.D. 1996. Requisite role of angiopoietin-1: A ligand for the TIE2 receptor, during embryonic angiogenesis. Cell 87: 1171-1180.

Suzuki, A., Yamaguchi, M.T., Ohteki, T., Sasaki, T., Kaisho, T., Kimura, Y., Yoshida, R., Wakeham, A., Higuchi, T., Fukumoto, M., et al. 2001. T cell-specific loss of Pten leads to defects in central and peripheral tolerance. Immunity 14: 523-534.

Terauchi, Y., Tsuji, Y., Satoh, S., Minoura, H., Murakami, K., Okuno, A., Inukai, K., Asano, T., Kaburagi, Y., Ueki, K., et al. 1999. Increased insulin sensitivity and hypoglycaemia in mice lacking the $\mathrm{p} 85 \alpha$ subunit of phosphoinositide 3-kinase. Nat. Genet. 21: 230-235.

Ueki, K., Yballe, C.M., Brachmann, S.M., Vicent, D., Watt, J.M., Kahn, C.R., and Cantley, L.C. 2002. Increased insulin sensitivity in mice lacking $\mathrm{p} 85 \beta$ subunit of phosphoinositide 3-kinase. Proc. Natl. Acad. Sci. 99: 419-424.

Wang, H.U., Chen, Z.F., and Anderson, D.J. 1998. Molecular distinction and angiogenic interaction between embryonic arteries and veins revealed by ephrin-B2 and its receptor EphB4. Cell 93: 741-753.

Yamaguchi, T.P., Dumont, D.J., Conlon, R.A., Breitman, M.L., and Rossant, J. 1993. flk-1, an flt-related receptor tyrosine kinase, is an early marker for endothelial cell precursors. Development 118: 489-498.

Zeng, X., Wert, S.E., Federici, R., Peters, K.G., and Whitsett, J.A. 1998. VEGF enhances pulmonary vasculogenesis and disrupts lung morphogenesis in vivo. Dev. Dyn. 211: 215-227.

Zhang, T., Chen, X., Qu, L., Wu, J., Cui, R., and Zhao, Y. 2004. Chrysin and its phosphate ester inhibit cell proliferation and induce apoptosis in Hela cells. Bioorg. Med. Chem. 12: 60976105. 


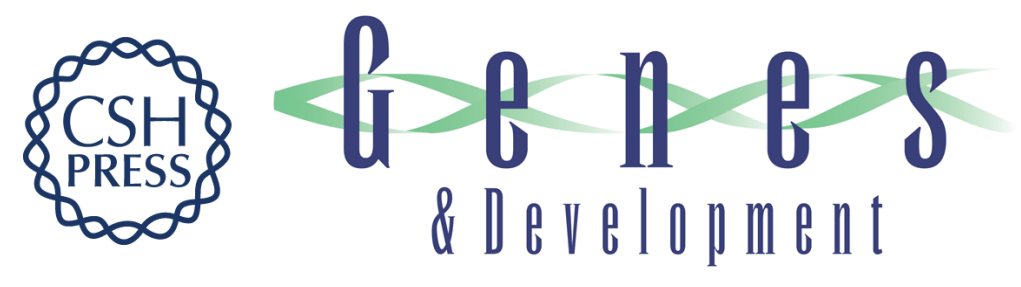

\section{The PTEN/PI3K pathway governs normal vascular development and tumor angiogenesis}

Koichi Hamada, Takehiko Sasaki, Pandelakis A. Koni, et al.

Genes Dev. 2005, 19:

Access the most recent version at doi:10.1101/gad.1308805

\section{Supplemental http://genesdev.cshlp.org/content/suppl/2007/03/14/gad.1308805.DC1 Material}

References This article cites 56 articles, 36 of which can be accessed free at: http://genesdev.cshlp.org/content/19/17/2054.full.html\#ref-list-1

\section{License}

Email Alerting

Receive free email alerts when new articles cite this article - sign up in the box at the top Service 